

\title{
Life management concepts of transformer investigations
}

\author{
K Vinoth Kumar ${ }^{*}$, Nithin Matthew Sam², Kevin Sony ${ }^{3}$ \\ 1,2 Department of EEE, Karunya Institute of Technology and Sciences, Coimbatore 641114, Tamil Nadu \\ ${ }^{3}$ Department of CSE, Karunya Institute of Technology and Sciences, Coimbatore 641114, Tamil Nadu \\ *Corresponding authorE-mail: kvinoth_kumar84@yahoo.in,
}

\begin{abstract}
This paper shows the importance of specifications and life management concepts for reliable, uninterrupted and intended application of transformers throughout the life cycle. The transformers are tested, manufactured and designed based on the specification.
\end{abstract}

Keywords: Power Transformers; Fault, Lifetime Of Transformers.

\section{Introduction}

One of the largest and costliest equipment in the transmission network is the power transformers and shunt reactors. Transformers being a long delivery item, reliable performance of this equipment is very important to maintain the availability of power system.

The transformers are tested, manufactured and designed based on the specification. With the growth in the size of power system and complexities of modern system, the adequacy of transformer specification plays a major role in its reliability. A good specification must properly consider the effect of application, system operating conditions, environmental considerations, site details, service conditions, termination details, etc. so that the transformer is designed for the conditions under which it has to operate. Thus the adequacy of specification of transformers, particularly, that of high voltage and larger rating assumes tremendous importance and an inadequate specification can lead to a deficient design and poor reliability.

\section{Specification Objectives}

The various parts of transformers viz magnetic circuit, insulation system, termination, cooling equipment etc. are designed as per technical specification details. A technical specification has three objectives:

i) To provide the tendered or manufacturer, with all that technical information necessary to carry out his design and which will vary for each design, for example rating, voltage ratio, type of cooling, losses, applicable tolerances on performance parameters, applicable standards, tests requirements etc.

ii) To provide the tendered, or manufacturer, with an indication of strategic importance of the transformer and the value to be placed on reliability, maintainability and long service life.

The specification should be a crystal clear information to designers without leaving any chance of ambiguity, particularly, each parameters defined in clear terms of unit in the technical specification with or without any tolerance.

\section{Life Management Concepts}

Transformer Life Management help the customers on secure high reliability and gain in-depth knowledge of the condition of the transformer. Life Management concepts of a transformer is a very vast subject, which deals with many activities like environmental conditions maintained during manufacturing storage, installation and commissioning. Also condition assessment by on line monitoring and diagnostic testing to assess the condition of oil and insulation material used in the transformer. On the topic, we have covered the effect of environmental factors and insulation ageing factors on the life of the transformer. Also I have presented some related case studies for better understanding of subject.

\section{A. Enivornmental Factors}

First and foremost requirement of any product to sustain for a long life particularly, electrical equipment like transformers is starting from its initial processes of manufacturing to installation and commissioning at site. Care shall be taken at each step for environmental conditions i.e. dust, moisture, metal particles, etc. which need to be individually dealt critically as these are the main constituents and putting direct consequences on equipment life. Effect of these factors explained below:

Dust: The transformer EHV class must be manufactured in dust proof chamber so that dust cannot enter into the job and reduce its service life, the presence of dust particles in the job givers higher partial discharge and one should not negotiate/ avoid/ overlook such for good health of transformer. People don't allow manufacturing in such environment even for $132 \mathrm{KV}$ Class of transformer and insisting for all voltage class.

Moisture: The content of moisture even in one part of 1000 is so dangerous that it can lead the transformer to fail in few months. Hence, IS \& IEC is very particular to agree certain PPM for each voltage class and in general my views not to allow any job with above 5PPM for at least EHV class of transformer. Moisture in combination with temperature accelerates the ageing of cellulosic insulation material used in transformers, which in turn reduces the life of transformer. Impact of temperature and moisture on the lifetime of transformer is explained in detail as under. 
Metals Particles: Windings, insulation and active parts of a transformer should not be exposed to the forced air/ gasses having metallic dust flying due to grinding or other operation like turning, milling and surfacing of conductive parts which are dangerous and under influence of electric charges it forms a local cell and in course of time it deteriorates the insulation property and starts ageing and becomes more and more conductive in nature. Thus failure of job occurs in short span of life. To avoid such situation to prevail, it is always suggested that the machine shop should be kept away from the manufacturing point of electrical appliances.

\section{B. Insulation Ageing Characteristics \& Related Case Studies}

When a transformer is manufactured in the factory, the paper insulated windings are subjected to drying before they are oil impregnated. At this state, the transformer has a moisture content of $<0.5 \%$ by weight in paper and $6 \mathrm{ppm}$ in oil. As the transformer ages, the moistures content will increase progressively at a rate of $0.1 \%$ to $0.2 \%$ / year. In severely deteriorated system, the moisture content could reach $>4 \%$.

Insulation aging is directly related to moisture content. During manufacturing process the drying out procedure is carried out as per manufacturing norms. There are possible areas of ingress of moisture in the insulation during the course of manufacturing of transformer i.e. excess hours taken when the CCA is taken out from oven or VPD for tanking, use of unprocessed insulation blocks during tanking. To avoid ingress of moisture in insulation, exposure time during tanking process to be minimized.

After tanking, testing is completed at works, the transformer (>50MVA) may be dispatched with nitrogen. In such cases dew point, relative humidity $(\mathrm{RH})$ of the nitrogen / dry air and gas pressure inside the transformer shall be checked and monitored On getting satisfactory results transformer shall be allowed for dispatch.

It is needless to say that after dispatch and during long storage, the transformer shall be monitored as per manufacturer's guidelines. In case of any damage noticed during transformer receipt at site, it shall be sealed immediately temporarily or permanently, as is possible and matter to be brought to the notice of the manufacturer.

\section{Case Studies on the incidences of Moisture Ingress}

\section{MVA, 132/33kV transformer}

After complete processing by end user the transformer was made ready for testing and charging. It has been informed by the customer that all other electrical test were in order except the IR values are not matching with factory test results. After thorough investigation, it has been observed that porcelain bushing was damaged during transportation and it could not be noticed at the time of receipt of transformer at site, same is shown in photo-1 below. Since the substation work was delayed due to delay in project, priority was not given to transformer erection and commissioning, and the transformer was without nitrogen for 2 years, resulting in ingress of moisture. Rusting on core lamination below bushing was noticed.

From the officials, it is understood that the transformer was idle for more than two years, No nitrogen pressure was monitored. Internal inspection was not carried out before erection of the transformer and directly bushing erection, vacuuming and oil filling and filtration was done. When the transformer is tested, it has been noticed that IR value is less as compared to factory test results. Hence, it was suggested to drain out the oil completely, carry out nitrogen purging cycles of drying out process, the IR values found satisfactory for charging the transformer. Thereafter, transformer was taken into service and now the said transformer is working satisfactory.

\section{MVA, 66/33kV Single Phase Transformer}

In this case also, the transformer was kept idle without charging for more than $1 \frac{1}{2}$ years and the area had huge humidity and no precaution was taken. When the transformer was taken for processing, it has been noticed that the HV-E IR value is less comparatively to other two combinations and w.r.t. factory test results. After thorough investigation of OLTC, oil view glass was found damaged which was not noticed by site officials, resulting ingress of huge moisture in OLTC chamber for longer duration. It was also noticed that though the transformer was oil filled condition, precaution was not taken for long storage as per the guidelines. Internal inspection revealed that there was huge quantity of water in the transformer oil and also some particles of water noticed on core resulting rusting of core as well as OLTC diverter chamber. These phenomenon caused the utility to return back the transformer to manufacturing works for complete reprocessing for removal of foreign particles and improvement of IR values with huge cost. Controllers analyses for non-linear system [12-21].

\section{MVA, 220/132kV Transformer}

The transformer was supplied and was kept idle for more than 2 years. When it was taken into system, it was noticed that there is drastic deterioration of IR value and all other electrical test were in order. When the matter came for discussion, it is revealed that the transformer was idle without monitoring of nitrogen for more than 2 years and after detailed discussions, it was decided to do the internal inspection to check the clearance of leads and if any nonconformity. After draining of oil it has been noticed that there is sludge over the windings. During further investigation, it has been noticed that the appearance of oil was found dark brown in new transformer. When investigating the reason of oil color change, it came to notice that customer has used oil from another 100MWA which was failed after service of more than 20 years. The idle unattended storage lead to ingress of their contaminants. For making transformer ready for service, it was decided to remove sludge/ contaminants by hot oil jet wash and replacement of oil by new. After site processing of transformer by hot oil filtration satisfactory IR values were achieved and transformer was taken into service.

\section{MVA, 132/33kV Transformer}

In other case, we found that the IR value measured at factory was not achieved during the commissioning of 63 MVA, 132/ 33kV. After detailed study and investigation, it has been noted that the transformer was supplied with nitrogen filled and oil was supplied separately in tankers. The oil samples drawn from oil tanker were found in order in all respect. The filtration machine which was used for this new transformer was used earlier for failed transformer oil processing and the same machine was used without cleaning of oil chamber for removal of contaminated oil. Thereafter, new high vacuum filter machine was used for achieving satisfactory results.

In many of the cases, we have found that moisture, dusts in oil are ingresses due to the improper care taken at the time of commissioning. Oil drums are kept vertical instead of horizontal Filter machine, Suction \& delivery pipes and storage tanks are not used for a long period resulting in heavy deposition of sedimentation and impurities which are not checked for its internal condition and cleaned before oil filling and filtration resulting ingress of moisture.

\section{Conclusion}

In view above it is recommended to check the following things to avoid ingress of moisture during the commissioning stage: 
Monitor the gas pressure inside the transformer during storage at site. Storage in gas filled condition shall be limited to six months duration. For storage more than 6 months, transformer shall be stored in oil filled condition. Store oil drums in horizontal position with bangs at 45 degree. Check the oil parameters supplied in tanker/ drums before filling in transformer. Do the internal inspections of transformer and check thoroughly for presence of any foreign particles inside the transformer; if observed clean it thoroughly. Check the filtration machine chamber is cleaned it is used for new transformer. Check the oil storage tank used for filtration machine is having oil resistance paint on inside surfaces and is in good condition. Use the storage tank after cleaning.

Breathers of transformers shall be maintained in healthy condition by periodical reconditioning

\section{References}

[1] S. Kundu, P.M. Yadav, Ratnesh Talesana, "Design Reviews and Life managemet Concepts," Electrical India Magazine, P P. No.28-38, July 2017.

[2] Text book "Transformer Engineering" by L.F. Blume, A.Boyajian, G.Camilli, T.C. Lennox, S. Minneci and V.M. Montsinger.

[3] IEC 60076-1. International Standard for Power Transformers Part 1: General.

[4] Life estimation techniques for transformer insulation,Power Engineering Conference (AUPEC), 2013 Australasian Universities.

[5] N. Lelekakis, D. Martin, W. Guo, J. Wijaya, M. Lee, "A field study of two online dry-out methods for power transformers", IEEE Electr. Insul. Mag., vol. 28, no. 3, pp. 32-39, May 2012.

[6] V. M. Montsinger, "Loading transformers by temperature", AIEE Trans., vol. 49, pp. 776-792, 1930

[7] D. H. Shroff, A. W. Stannett, "A review of paper aging in transformers", IEE Proc., vol. 132, no. 6, Nov. 1985.

[8] L. E. Lundgaard, W. Hansen, D. Linhjell, T. J. Painter, "Aging of oil-impregnated paper in power transformers", IEEE Trans. Power Del., vol. 19, no. 1, pp. 230-239, Jan. 2004.

[9] D. Martin, Y. Cui, T. Saha, N. Lelekakis, J. Wijaya, "Life estimation techniques for transformers insulation", IEEE Australasian Univ. Power Eng. Conf., 2013.

[10] Power transformers part 7: Loading guide for oil-immersed power transformers", IEC 60076-7, IEC, Switzerland, 2005.

[11] N. Lelekakis, D. Martin, W. Guo, 1. Wijaya, and M. Lee, "A field study of two online dry-out methodsfor power transformers", IEEE Electrical Insulation Magazine, Vol. 28, pp. $32-39,2012$

[12] R. Kalaivani, K. Ramash Kumar, S. Jeevananthan, "Implementation of VSBSMC plus PDIC for Fundamental Positive Output Super Lift-Luo Converter," Journal of Electrical Engineering, Vol. 16, Edition: 4, 2016, pp. 243-258.

[13] K. Ramash Kumar,"'Implementation of Sliding Mode Controller plus Proportional Integral Controller for Negative Output Elementary Boost Converter," Alexandria Engineering Journa (Elsevier), 2016, Vol. 55, No. 2, pp. 1429-1445.

[14] P. Sivakumar, V. Rajasekaran, K. Ramash Kumar, "Investigation of Intelligent Controllers for Varibale Speeed PFC Buck-Boost Rectifier Fed BLDC Motor Drive," Journal of Electrical Engineering (Romania), Vol.17, No.4, 2017, pp. 459471

[15] K. Ramash Kumar, D.Kalyankumar, DR.V.Kirbakaran” An Hybrid Multi level Inverter Based DSTATCOM Control, Majles Journal of Electrical Engineering, Vol. 5. No. 2, pp. 17-22, June 2011, ISSN: 0000-0388.

[16] K. Ramash Kumar, S. Jeevananthan, "A Sliding Mode Control for Positive Output Elementary Luo Converter," Journal of Electrical Engineering, Volume 10/4, December 2010, pp. 115127.

[17] K. Ramash Kumar, Dr.S. Jeevananthan,” Design of a Hybrid Posicast Control for a DC-DC Boost Converter Operated in Continuous Conduction Mode" (IEEE-conference PROCEEDINGS OF ICETECT 2011), pp-240-248, 978-1-42447925-2/11.

[18] K. Ramash Kumar, Dr. S. Jeevananthan,” Design of Sliding Mode Control for Negative Output Elementary Super Lift Luo Converter Operated in Continuous Conduction Mode", (IEEE conference Proceeding of ICCCCT-2010), pp. 138-148, 978-14244-7768-5/10.
[19] K. Ramash Kumar, S. Jeevananthan, S. Ramamurthy" Improved Performance of the Positive Output Elementary Split Inductor-Type Boost Converter using Sliding Mode Controller plus Fuzzy Logic Controller, WSEAS TRANSACTIONS on SYSTEMS and CONTROL, Volume 9, 2014, pp. 215-228.

[20] N. Arunkumar, T.S. Sivakumaran, K. Ramash Kumar, S. Saranya, "Reduced Order Linear Quadratic Regulator plus Proportional Double Integral Based Controller for a Positive Output Elementary Super Lift Luo-Converter," JOURNAL OF THEORETICAL AND APPLIED INFORMATION TECHNOLOGY, July 2014. Vol. 65 No.3, pp. 890-901.

[21] Arunkumar, T.S. Sivakumaran, K. Ramash Kumar, "Improved Performance of Linear Quadratic Regulator plus Fuzzy Logic Controller for Positive Output Super Lift Luo-Converter," Journal of Electrical Engineering, Vol. 16, Edition:3, 2016, pp 397-408.

[22] T. Padmapriya and V. Saminadan, "Distributed Load Balancing for Multiuser Multi-class Traffic in MIMO LTE-Advanced Networks", Research Journal of Applied Sciences, Engineering and Technology (RJASET) - Maxwell Scientific Organization ISSN: 2040-7459; e-ISSN: 2040-7467, vol.12, no.8, pp:813-822, April 2016.

[23] S.V.Manikanthan and D.Sugandhi "Interference Alignment Techniques For Mimo Multicell Based On Relay Interference Broadcast Channel " International Journal of Emerging Technology in Computer Science \& Electronics (IJETCSE) ISSN: 0976-1353 Volume- 7 ,Issue 1 -MARCH 2014.

[24] P Bala Gopal, K Hari Kishore, B.Praveen Kittu "An FPGA Implementation of On Chip UART Testing with BIST Techniques", International Journal of Applied Engineering Research, ISSN 0973-4562, Volume 10, Number 14 , pp. 34047 34051, August 2015

[25] Arunkumar, T.S. Sivakumaran, K. Ramash Kumar, "Improved Performance of Linear Quadratic Regulator plus Fuzzy Logic Controller for Positive Output Super Lift Luo-Converter," Journal of Electrical Engineering, Vol. 16, Edition:3, 2016, pp. 397-408. 